or delivery and had been taking phenobarbitone and phenytoin for many years. At 2 days of age the baby was jittery and required sedation with diazepam for 48 hours. He was a slow and difficult feeder in hospital and this feeding pattern continued throughout infancy.

He presented again at age $31 / 2$ years as a slow talker. His medical history showed some delay in gross motor milestones; he had first sat unsupported at age 10 months and walked independently at two years. On examination his height was on the 10th centile, weight on the third centile, and head circumference on the 50th centile. He had pointed incisors and generally poor teeth enamel. He had a paraumbilical hernia and incurving of the fourth toes bilaterally. His vision and hearing were normal.

A Stanford-Binet assessment gave an intelligence quotient between 70 and 80 . All investigations as to the cause of his mild mental retardation and speech delay were negative. A Reynell assessment at age 5.3 years showed that his comprehension of language was delayed by $2.2 \mathrm{SD}$ and his expressive skills by more than $3 \mathrm{SD}$. A cinepalatogram at age 7 years showed normal palate structure but severe functional abnormalities similar to those described in our first patient. His soft palate rarely met the posterior pharyngeal wall at all, with gross incompetence when he swallowed or attempted to produce speech sounds.

\section{Discussion}

The first report of a higher than expected incidence of congenital abnormalities in the children of mothers with epilepsy was in $1968 .^{2}$ Since then evidence from animal studies has stengthened the view that anticonvulsants, particularly phenobarbitone and phenytoin, may be teratogenic. ${ }^{34}$ Our patients had clear histories of antenatal exposure to phenobarbitone and phenytoin. They show similar characteristics of short stature, mild hypotonia, delayed gross motor milestones, poor dentition, and mild mental retardation. Some of these features have already been described in children born to mothers taking phenobarbitone and phenytoin in pregnancy. ${ }^{56}$ Functional palatal incompetence has not been decribed previously in the fetal anticonvulsant syndrome but we believe it may be an additional variable feature.

\section{References \\ 1 Meadow R. The teratogenicity of epilepsy. Dev Med Child Neurol 1974:16:376. \\ 2 Meadow SR. Anticonvulsant drugs and congenital abnormali- ties. Lancet 1968:ii: 1296. \\ ${ }^{3}$ Mackler B, Grave R, Tippet DF, et al. Studies of the development of congenital anomalics in rats. III. Effects of inhibition of mitochondrial energy systems on embryonic development. Teratology 1975;12:291-6. \\ ${ }^{4}$ Fritz H, Muller D, Hess R. Comparative study of the teratogenicity of phenobarbitone, diphenylhydration and carba- mazepine in mice. Toxicology 1976;6:323-30. \\ 5 Seip M. Growth retardation, dysmorphic facies and minor malformation following massive exposure to phenobarbitone in utcro. Acta Paediatr Scand 1976;65:617-21. \\ ${ }^{6}$ Hanson JW, Smith DW. The fetal hydantoin syndrome. J Pediatr 1975;87:285.}

Correspondence to Dr K N Pearl, Department of Paediatrics, Charing Cross Hospital Medical School, Fulham Palace Road, London W6 8RF.

Received 14 May 1984

\title{
Subcutaneous emphysema: a new form of self abuse
}

\author{
M E McGRAW, D A PRICE, AND R J POSTLETHWAITE
}

Royal Manchester Children's Hospital

SUMMARY Subcutaneous emphysema is usually the result of trauma or surgery. We report an unusual case of a disturbed adolescent who presented with cervicofacial emphysema as a result of self abuse.

Subcutaneous emphysema may develop after tears in the gastrointestinal, genitourinary, and respiratory systems and from the entry of gas-forming organisms into the subcutaneous tissues. Cervicofa- cial emphysema has been described in association with dental procedures, the Valsalva manoeuvre, traumatic injury or surgery involving the air sinuses, and in association with pneumomediastinum. We report an unusual case of recurrent cervicofacial emphysema.

\section{Case report}

A 15 year old boy presented to the emergency department with a 12 hour history of facial swelling. 
He reported he had been leaning out of a window when he felt something hit his cheek. There was no apparent injury but shortly afterwards he developed facial swelling which became progressively worse. Apart from mild asthma which required no treatment, he had previously been well. A noticeable unilateral periorbital and facial subcutaneous emphysema extending downwards towards the neck was found on examination (Figure). A tiny puncture mark was noted in the skin but no corresponding buccal lesion was detectable. Sinus radiographs were normal and his signs settled spontaneously.

He presented four months later with similar physical findings. On this occasion there was no history of possible preceding injury and subcutaneous emphysema alone was present with no evidence of any skin trauma. He denied any unusual activities despite repeated questioning. He seemed very anxious about his symptoms and was reluctant to be discharged from hospital until they had completely settled. Extensive investigation including sinus and chest radiographs, lung scan, and barium swallow were all normal. Further questioning showed an unhappy social background. His parents were divorced and the boy was in the

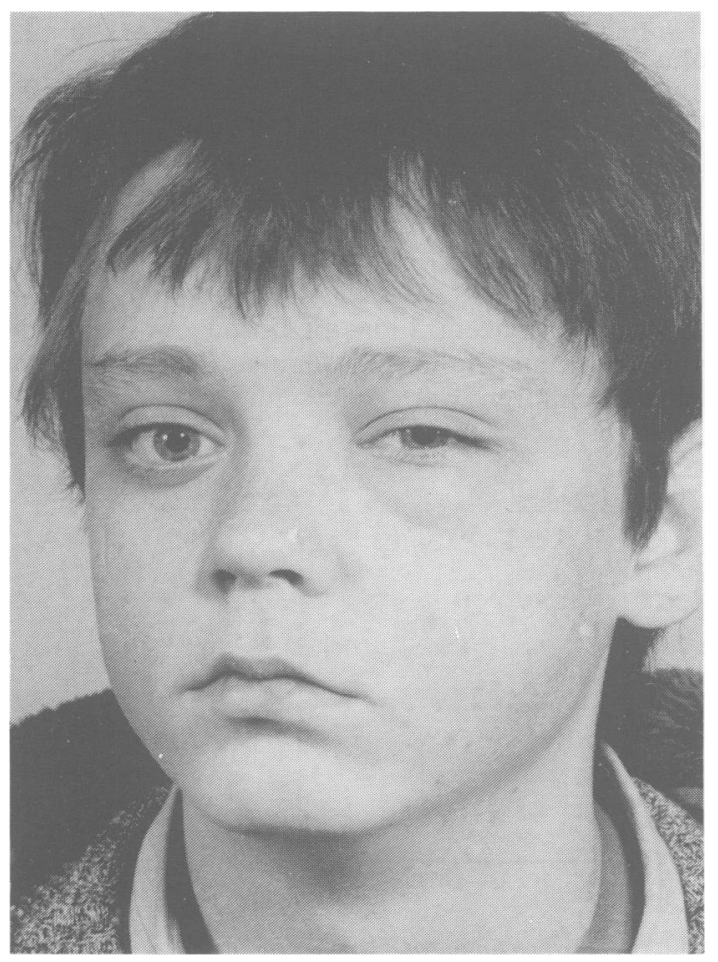

Figure Unilateral cervicofacial emphysema: self induced. custody of his father, who had recently remarried. $\mathrm{He}$ had subsequently been rejected by his stepmother and had run away on several occasions. Although a diagnosis of self induced emphysema was entertained, the mechanism by which it had been produced was unclear.

He presented for a third time two weeks later. On this occasion both he and a friend had identical physical findings of unilateral facial subcutaneous emphysema. When questioned this time, however, a confession was obtained. On the first occasion he had been attempting to introduce an earring into his cheek. He pierced the buccal mucosa with a sewing needle then pushed the needle through the full thickness of the cheek to create a hole. In an attempt to facilitate introduction of the earring into the hole he had inflated his cheeks. He had been concerned about the subsequent swelling but had not dared confess the true aetiology. Thereafter, he had deliberately produced the symptoms in order to escape intolerable home circumstances. On the final occasion a friend had been persuaded to produce the same symptoms 'for fun'.

During this admission a formal psychiatric assessment was obtained. It was considered that attempts to return the boy to his family would carry considerable risk of further, possibly serious, self injury and thus foster care was obtained. He has continued to attempt to abscond and has inflicted self injury by a variety of alternative methods.

\section{Discussion}

Although subcutaneous emphysema is uncommon, its aetiology is usually readily apparent. Deliberate self induced emphysema has only rarely been reported. In three cases air was introduced into the subcutaneous tissues of the extremities by the use of a needle and a syringe. ${ }^{1-3}$ In a fourth case air was introduced into the scrotum by means of a cutting tool. $^{4}$

Activities which result in a rise in intra-oral pressure in the presence of a laceration of the buccal mucosa have been noted to result in cervicofacial emphysema ${ }^{5}$ and this is one of the mechanisms implicated in the development of emphysema after orthodontic procedures. Emphysema deliberately produced in this manner, however, has not been previously reported. In conclusion, should the aetiology of subcutaneous emphysema be unclear, a self induced cause should be considered.

\section{References}

1 Gershwin ME, Gude JK, Petralli J. Factitious subcutaneous emphysema. Ann Int Med 1971;75:585-7. 
${ }^{2}$ Rauh JL. Self induced subcutaneous emphysema in an adolescent. J Pediatr 1976;88:690-1.

${ }^{3}$ Craig RP, Boffard KD. Factitious subcutaneous emphysema: a case report. Injury 1977;8:307-9.

4 Srch M, Beran J. Sevstbeschadigung durch Verletzung des Hodensackes und subcutanes emphysema. $Z$ Rechtsmed 1973;72:73-4.
5 Lee JL, Bordenca CM. Self induced air emphysema of the face and neck. Oral Surg 1973;36:603-5.

Correspondence to Dr M E McGraw, Royal Manchester Children's Hospital, Pendlebury, Manchester M27 1HA.

Received 18 May 1984

\title{
Fibronectin in children with diabetes mellitus
}

\author{
U MUHAR, W GRANINGER, E SCHOBER, AND E SCHUSTER \\ Department of Paediatrics and Medicine and Institute of Medical Computer Science, University of Vienna, \\ Austria
}

SUMMARY Fibronectin plasma concentrations were determined in 28 children with type I diabetes mellitus and 22 healthy children. No statistically significant difference was observed between the fibronectin concentrations in diabetic and nondiabetic children. Even in children with poor glycaemic control the fibronectin concentrations (glycosylated haemoglobin greater than $10 \%$ ) were not significantly higher.

Fibronectin, a 440000 dalton glycoprotein, is a substrate for thrombin, plasmin, and activated fibrin stabilising factor (factor XIII). ${ }^{1}$ Acting as a nonspecific opsonin, plasma fibronectin potentiates reticulo-endothelial clearance of intravascular debris to maintain microvascular integrity and vascular permeability.

Both raised and normal fibronectin concentrations have been described in non-ketoacidotic adult patients with type I diabetes mellitus, ${ }^{23}$ while low fibronectin concentrations have been observed in diabetic ketoacidosis. ${ }^{4}$ A possible relation between high fibronectin concentrations and diabetic microangiopathy has been suggested. ${ }^{23}$

To our knowledge fibronectin concentrations have not been studied in diabetic children. We have, therefore, measured and compared plasma fibronectin concentrations in children with type I diabetes mellitus and healthy children.

\section{Patients and methods}

The diabetic group consisted of 28 patients (mean age 12 years, range $11 \cdot 1$ to 13.9 ) and 22 healthy children served as a reference group (mean age 11.8 years, range $10 \cdot 0$ to $13 \cdot 8$ ). There was no difference between the groups with regard to sex distribution, age, weight, and height. None of the children had exercised before blood sampling and none were receiving any medications, except insulin in the diabetic group. Blood samples were obtained by venipuncture after an overnight fast and before morning insulin. Fibronectin was determined by an immunoturbidimetric assay as described by Saba et al. ${ }^{5}$ Calibration was done using standard plasmas containing $1250,2500,5000$, and $7500 \mu \mathrm{g} / \mathrm{l}$. Glycosylated haemoglobin (expressed as a percentage of haemoglobin (rel \%)) was measured by a microcolumn technique (BIORAD).

For statistical analysis Kruskal-Wallis test, MannWhitney test, and Spearman rank correlation were used.

\section{Results}

The plasma concentrations of fibronectin for both groups are shown in the Figure. The values in diabetic children were not significantly different

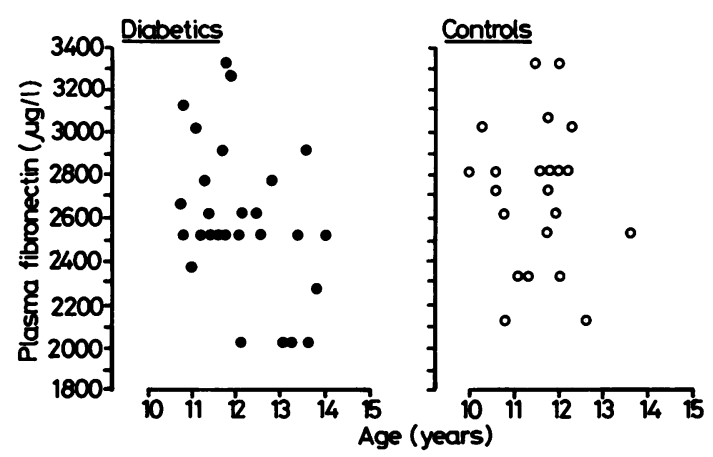

Figure Fibronectin plasma concentrations $(\mu g / l)$ in diabetic children and healthy controls. 